\title{
Determination of mercury content in pyrotechnics used for fireworks and firecrackers based on inductively coupled plasma optical emission spectrometric approach (ICP-OES)
}

\author{
Wu Jun-yi ${ }^{1, a}$, Xiao Huan-xin ${ }^{1, b}$ \\ ${ }^{1}$ Technical Center for Dangerous Goods Testing of Guangxi Entry-Exit Inspection and Quarantine \\ Bureau, Beihai, Guangxi, China \\ ajohnny-woo@vip.163.com \\ bxxciq@china.com
}

Keywords: fireworks and firecrackers; pyrotechnics; mercury content; determination; inductively coupled plasma optical emission spectrometric approach; ICP-OES.

Abstract. Inductively coupled plasma optical emission spectrometric approach(ICP-OES) is used to determine the mercury content in pyrotechnics used for fireworks and firecrackers. Element of mercury is commonly found as impurity in chemical materials used for pyrotechnics in fireworks and firecrackers. Statistical analysis shows that mercury content in pyrotechnics is below 5\%.Concept of this method: considering the weight of the sample is $400 \mathrm{mg}$,constant volume is $0.5 \mathrm{~L}$ and the concentration of mercury is below $40 \mathrm{mg} / \mathrm{L}$ in sample solution, the determination scope of the method for the mercury content would be below 5\%.Further experiments proved that the fitting correlation coefficient of mercury calibration curve is 0.995 or higher, recovery is $86.55 \%-95.19 \%$.The allowable differential value is $0.5 \%$ between two single tests under repeatable conditions. This method can completely satisfy the requirements of the fireworks and firecrackers industry with high accuracy and good precision.

\section{Introduction}

In China, fireworks and firecrackers are very important consumer recreational products in people's everyday life since ancient times. Gorgeous colors produced by fireworks and firecrackers are even the leading role of foiling festal atmosphere in every grand holiday celebrations. In recent years, with the rapid development of global trade, fireworks and firecrackers are becoming more and more popular all over the world, more and more consumers are fascinatedby different kinds of patterns, pictures, and sound effects of fireworks and firecrackers. Pyrotechnics used to produce various kinds of pyrotechnic effects in fireworks and firecrackers are consists of many different solid chemicals. Mercury element is commonly found in pyrotechnics as impurity in chemical materials used for pyrotechnics in fireworks and firecrackers, and which would seriously affect the environment. Quantitative analysis of chemical compositions in pyrotechnics such as mercury content is required under the Globally Harmonized System of Classification and Labeling of Chemicals(GHS)to be complemented in the fireworks and firecrackers industry. Meanwhile it will also provide a scientific and effective technical support to the management and supervision of safety production for the government, and improve products' quality level by the manufacturers. It can also be utilized as a tool in providing valuable data in the judgment in some major arbitration and security incident analysis. Quantitative analysis method of the mercury content reported in current literature is limited to traditional chemical analysis, such methods have the following disadvantages:(1) Long detecting period. Generally, it will take a skilled technician two whole days or so to complete the detection.(2) The operation is more complicated. It needs to go through many steps such as dissolving sample, filtration, precipitation collection, drying and weighing precipitation and ect. Comparing with traditional chemical analysis methods ,this method based on inductively coupled plasma optical emission spectrometric approach has the advantages of simple operation steps, short period of detection, high accuracy and good precision. 


\section{Theory}

Mercury element is commonly found as impurity in chemical materials such as aluminum powder, aluminum-magnesium alloy powder, copper oxide powder and so on in pyrotechnics in fireworks and firecrackers. Statistical analysis shows that the mercury content in pyrotechnics would not be above $5 \%$ as mass fraction.Concept of the method: considering the weight of the sample is $400 \mathrm{mg}$,constant volume is $0.5 \mathrm{~L}$ and the concentrations of the mercury is below $40 \mathrm{mg} / \mathrm{L}$ in sample solutions, the determination scope of the method for the mercury content is below $5 \%$.In accordance with the relevant safety regulations, the sample was ground into powder of less than 180 micron. Then the sample powder is placed in an explosive-proof oven at $50^{\circ} \mathrm{C}-55^{\circ} \mathrm{C}$ and dried for 4 hours, and then placed into a dryer for cooling down to room temperature. Pretreated sample is fully dissolved in $30 \mathrm{~mL}$ hydrochloric acid and then filtered into volumetric flask as sample solution. The sample solution is injected into the plasma as a light source, and we can measure the spectral intensity corresponding to the element wavelength in the plasma spectrometer. The actual content of mercury element in the sample can be calculated from the concentrations of the mercury reading by the calibration curve.

\section{Experiment section}

\section{Reagents}

Unless otherwise stated, all the reagents should be guaranteed reagents and pure water is secondary grade water as described in ISO 3696(1987). Hydrochloric acid (1+19): mix $10 \mathrm{~mL}$ hydrochloric acid and $190 \mathrm{~mL}$ pure water thoroughly. Standard solution of the mercury : mass concentration is $1,000 \mathrm{mg} / \mathrm{L}$. Standard working solution of the mercury: separately pipette the standard solution of mercury with volume $0 \mathrm{~mL}, 0.1 \mathrm{~mL}, 0.5 \mathrm{~mL}, 1 \mathrm{~mL}, 2 \mathrm{~mL}$ and $5 \mathrm{~mL}$ into four $100 \mathrm{mLv}$ lumetric flasks, and add hydrochloric acid solution $(1+19)$ to reach $100 \mathrm{~mL}$ in each volumetric flask, mix thoroughly for later use.Concentrations of the standard working solution in different flasks are shown in Table 1.

Table 1 Concentrations of series standard working solutions of mercury $\mathrm{mg} / \mathrm{L}$

\begin{tabular}{|l|l|l|l|l|l|l|}
\hline \multirow{2}{*}{ element } & \multicolumn{6}{l|}{ concentrations of series standard working solutions } \\
\cline { 2 - 7 } & $\mathrm{N} 1$ & $\mathrm{~N} 2$ & $\mathrm{~N} 3$ & $\mathrm{~N} 4$ & N5 & N6 \\
\hline $\mathrm{Hg}$ & 0 & 1 & 5 & 10 & 20 & 50 \\
\hline
\end{tabular}

\section{Instrument and apparatus}

Explosive-proof oven with accuracy to $\pm 2^{\circ} \mathrm{C}$. Analytical balance with accuracy to $0.1 \mathrm{mg}$. Inductively coupled plasma atomic emission spectrometer (ICP-OES): United States Thermo Fisher (former Thermo Electron Corporation) Company iCAP6300 series.

\section{Operation step}

(1) Weigh the sample of about $400 \mathrm{mg}$, accuracy to $0.1 \mathrm{mg}$.

(2) Place the sample into a clean $300 \mathrm{~mL}$ beaker, add $30 \mathrm{~mL}$ hydrochloric acid into the beaker, then place the beaker on an electric stove to make the solution boiled for about $20 \mathrm{~min}$. Filter the solution through filter paper to an $0.5 \mathrm{~L}$ volumetric flask, wash the beaker and the filter paper several times 
with pure water, and make a constant volume after the filtered solution cooling down to room temperature.

(3) Parameters of the ICP-OES instrument parameters are shown in Table 2.

Table 2Parameters of the ICP-OES instrument

\begin{tabular}{|l|l|}
\hline parameters lelement & $\mathrm{Hg}$ \\
\hline Flush pump speed & $100 \mathrm{rpm}$ \\
\hline Analysis pump speed & $75 \mathrm{rpm}$ \\
\hline Pump stable time & $5 \mathrm{~s}$ \\
\hline Tube Type & Polyethylene Orange / White \\
\hline RF power & $1150 \mathrm{w}$ \\
\hline Auxiliary gas flow & $0.5 \mathrm{~L} / \mathrm{min}$ \\
\hline Nebulizer gas flow & $0.70 \mathrm{~L} / \mathrm{min}$ \\
\hline Vertical viewing height & $12 \mathrm{~mm}$ \\
\hline Spectral line & $\mathrm{Hg} 1849, \mathrm{Hg} 2536$ \\
\hline Repeat times & 3 \\
\hline
\end{tabular}

(4) Calibration (working) curve: according to the requirements of the method and the instrument criteria, we set the instrument to optimum analysis conditions, and adjust it to the best working condition, and determine spectral intensity of the series standard solution from $\mathrm{N}_{1}$ to $\mathrm{N}_{6}$ to establish the calibration (working) curve with the elemental concentrations as independent variable and the spectral intensity as the dependent variable. The linear correlation coefficient of the regression curve should be 0.995 or higher.

(5) Sample determination: determine the spectral intensity of the mercury in blank solution and every sample solution under the best analysis condition and read the concentrations from the calibration curve according to the spectral intensity.

\section{Results calculation}

Content of the mercury element in the sample can be calculated as mass fraction $W$ and its value shown in\% according to the following formula.

$$
W=\frac{c V}{m} \times 100 \%
$$

Where: $c$ - concentration of the mercury element in the sample solution read by ICP-OES in mg/L; $V$-constant volume of the volumetric flask used for the sample solution, expressed in liters(L); $m$-quantity of the sample, expressed in milligrams (mg).

$W$ - the content of the mercury in the sample, expressed in \%.

\section{Experimental data and analysis}

\section{Recovery test}

To assess the accuracy of the method, we used the standard substances addition recovery test. We added the mercury standard substance to some actual pyrotechnic samples, dissolved the samples and determined the contents of mercury in the sample solution. The values of the mercury contents we measured are compared with the theoretical ones, and the experimental data is shown in Table 3 below. 
Table 3 Recovery test results

\begin{tabular}{|c|c|c|c|c|c|c|c|}
\hline $\begin{array}{l}\text { Elements } \\
\text { line }\end{array}$ & $\begin{array}{l}\text { Theoretical } \\
\text { concentrati } \\
\text { ons of the } \\
\text { sample } \\
\text { solution } \\
\text { (mg/L ) }\end{array}$ & $\begin{array}{l}\text { Measured } \\
\text { concentrati } \\
\text { ons of the } \\
\text { sample } \\
\text { solution } \\
(\mathrm{mg} / \mathrm{L})\end{array}$ & $\begin{array}{l}\text { Theoretical } \\
\text { quality } \\
\text { contents of } \\
\text { the sample } \\
\text { (\%) }\end{array}$ & $\begin{array}{l}\text { Measured } \\
\text { quality } \\
\text { contents of } \\
\text { the sample } \\
(\%)\end{array}$ & $\begin{array}{l}\text { Absolute } \\
\text { deviation } \\
(\%)\end{array}$ & $\begin{array}{l}\text { Recovery } \\
(\%)\end{array}$ & $\begin{array}{l}\text { Concentration } \\
\text { range of the } \\
\text { calibration } \\
\text { curve }(\mathrm{mg} / \mathrm{L})\end{array}$ \\
\hline \multirow{6}{*}{ Hg1849 } & 6.84 & 5.92 & 0.43 & 0.37 & 0.06 & 86.55 & \multirow{6}{*}{$1-50$} \\
\hline & 16.38 & 15.11 & 1.02 & 0.94 & 0.08 & 92.25 & \\
\hline & 23.67 & 22.18 & 1.48 & 1.39 & 0.09 & 93.71 & \\
\hline & 31.15 & 29.56 & 1.95 & 1.85 & 0.10 & 94.90 & \\
\hline & 38.50 & 36.44 & 2.41 & 2.28 & 0.13 & 94.64 & \\
\hline & 42.15 & 40.12 & 2.63 & 2.51 & 0.13 & 95.19 & \\
\hline
\end{tabular}

\section{Precision test}

The precision of the method is expressed in the allowable differential value between two single tests under repeatable conditions. The contents of the mercury in actual pyrotechnics is below $5 \%$.Three samples of different mercury contents to be determined under the same condition over a period of time(almost two months).Each sample was repeatedly measured in 4 rounds with 11 measurements in each round. We calculated the allowable differential values under repeatable conditions, and the results are listed in the Table 4 below.

Table 4 Precision test results

\begin{tabular}{|c|c|c|c|c|c|c|c|c|c|c|}
\hline No. & rounds & \multicolumn{6}{|c|}{ Values (\%) } & $\begin{array}{l}\text { Standard } \\
\text { deviation of } \\
\text { each round }\end{array}$ & $\begin{array}{l}\text { Standard } \\
\text { deviation of } \\
\text { the } \\
\text { repeatable }\end{array}$ & $\begin{array}{l}\text { Allowable } \\
\text { differentia } \\
\text { l values }\end{array}$ \\
\hline \multirow{8}{*}{01} & \multirow{2}{*}{1} & 2.78 & 2.64 & 2.12 & 3.34 & 2.85 & 3.54 & \multirow{2}{*}{0.1595} & \multirow{8}{*}{0.1627} & \multirow{8}{*}{0.4605} \\
\hline & & 2.34 & 3.87 & 2.81 & 2.52 & 3.21 & & & & \\
\hline & \multirow{2}{*}{2} & 2.12 & 3.98 & 2.83 & 2.86 & 2.85 & 2.89 & \multirow{2}{*}{0.1656} & & \\
\hline & & 3.54 & 2.72 & 2.81 & 3.89 & 2.89 & & & & \\
\hline & \multirow{2}{*}{3} & 2.12 & 2.84 & 2.83 & 2.78 & 2.21 & 2.89 & \multirow{2}{*}{0.1590} & & \\
\hline & & 3.98 & 2.75 & 2.13 & 2.82 & 2.32 & & & & \\
\hline & \multirow{2}{*}{4} & 2.86 & 2.84 & 2.53 & 2.73 & 3.98 & 2.89 & \multirow{2}{*}{0.1669} & & \\
\hline & & 2.32 & 2.73 & 3.76 & 2.82 & 2.11 & & & & \\
\hline \multirow{8}{*}{02} & \multirow{2}{*}{1} & 3.78 & 3.64 & 3.12 & 3.34 & 3.85 & 3.54 & \multirow{2}{*}{0.1652} & \multirow{8}{*}{0.1680} & \multirow{8}{*}{0.4754} \\
\hline & & 3.34 & 4.87 & 3.81 & 4.56 & 3.21 & & & & \\
\hline & \multirow{2}{*}{2} & 4.56 & 3.98 & 3.83 & 3.86 & 3.85 & 3.89 & \multirow{2}{*}{0.1704} & & \\
\hline & & 2.34 & 3.11 & 3.81 & 3.89 & 3.89 & & & & \\
\hline & \multirow{2}{*}{3} & 2.87 & 4.34 & 3.83 & 3.78 & 3.21 & 3.89 & \multirow{2}{*}{0.1618} & & \\
\hline & & 3.98 & 4.21 & 3.13 & 4.53 & 3.32 & & & & \\
\hline & \multirow{2}{*}{4} & 2.34 & 3.84 & 3.53 & 3.73 & 3.98 & 3.89 & \multirow{2}{*}{0.1746} & & \\
\hline & & 3.32 & 3.73 & 3.76 & 4.65 & 3.11 & & & & \\
\hline \multirow{5}{*}{03} & \multirow{2}{*}{1} & 4.78 & 4.64 & 4.12 & 4.34 & 4.85 & 4.54 & \multirow{2}{*}{0.1635} & \multirow{5}{*}{0.1670} & \multirow{5}{*}{0.4727} \\
\hline & & 3.34 & 4.87 & 4.81 & 3.45 & 4.21 & & & & \\
\hline & \multirow{2}{*}{2} & 4.56 & 4.98 & 4.83 & 4.86 & 4.85 & 4.89 & \multirow{2}{*}{0.1593} & & \\
\hline & & 3.21 & 4.11 & 4.81 & 4.89 & 4.89 & & & & \\
\hline & 3 & 2.87 & 4.34 & 4.83 & 4.78 & 4.21 & 4.89 & 0.1761 & & \\
\hline
\end{tabular}




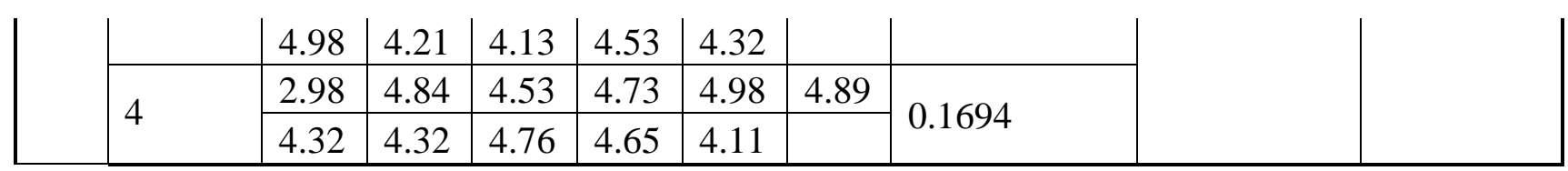

\section{Explanation of the results calculation in table 4 :}

Standard deviation of each round (Si) refers to the standard deviation of a sample which has been measured parallel for $n$ times under the same condition in the same time span and calculated as follow :

$$
S_{i}=\sqrt{\frac{\sum_{i=1}^{n}\left(X_{i}-\bar{X}\right)^{2}}{n-1}}
$$

$\mathrm{X}_{\mathrm{i}}$ - value of the $\mathrm{i}$-th parallel measurement;

$\bar{X}-$ average value of $n$ times parallel measurements;

$\mathrm{n}$ - number times of parallel measurements.

Standard deviation of the repeatable measurements $\operatorname{Sr}(\%)$ refer to the standard deviation of a sample which has been measured parallel for $m$ times under the same condition in different time. Different time interval refers to the period of time interval in which we can maintain the same determined conditions, so the precision of $\mathrm{m}$ rounds repeatable measurements are equivalent. Standard deviation(Sr) is calculated as follow :

$$
S_{r}=\sqrt{\frac{\sum S_{i}^{2}}{m}}
$$

$\mathrm{S}_{\mathrm{i}}-$ standard deviation of the $\mathrm{i}$-th round of $\mathrm{n}$ times parallel measurements.

$\mathrm{M}$-number of times of parallel measurements.

The allowable differential value(Ir) refers to the possibility of the absolute difference exceeding Ir between any two results is only 5\% (when the probability with 95\% confidence) which are measured with the same sample by the same method in the same condition. The allowable differential value(Ir) is calculated as follow:

$\mathrm{Ir}=2.83 \mathrm{Sr}$

As we can see from Table 4,the allowable differential values of mercury in this method is $0.5 \%$.

\section{Conclusions}

Inductively coupled plasma optical emission spectrometric approach(ICP-OES) is used to determine the mercury content in pyrotechnics used for fireworks and firecrackers, this method is accurate and quick with high accuracy and good precision. When the mercury content in the sample is below $5 \%$ as mass fraction, the recovery is $86.55 \%-95.19 \%$. The allowable differential value was $0.5 \%$ between two single tests under repeatable conditions. In other word, this method can completely satisfy the requirements of the fireworks and firecrackers industry.

\section{References}

[1] ZHOU Tong-hui ,WANG Er-kang,LU Wan-zhen ect. Handbook in analytical chemistry(second edition), basic knowledge of and safety knowledge(the first volume), China Chemical industry press:pp.568-580,1997.

[2] KE Yi-kan ,DONG Hui-ru. Handbook in analytical chemistry(second edition), Spectral analysis(the third volume), China Chemical industry press:pp.18-212,1998.

[3] iCAP 6000 Series ICP-OES spectrometer user guide ,United States Thermo Fisher Company,2012 
[4] PANG guo-fang,GAO jian-wen, LIU yong-ming, Method for the determination of potassium, phosphorus,iron,calcium,zinc,aluminium,sodium,magnesium,boron,manganese,copper,barium,titani um,vanadium,nickel,cobalt,chromium contents in honey--Inductively coupled plasma atomic emission spectrometric method,GB/T 18932-2002(China national standard).

[5]CHEN Xi,LI Jing,GU Yong-ming,Determination of potassium and sodium in zinc oxide powder by inductively coupled plasma atomic emission spectrometry, Metallurgical Analysis, 33(10),2013. [6]HE Wen-Jian,WANG Hui,JIN Fang,Determination of Potassium, Sodium, Calcium, Magnesium and Sulfate Radical in Potassium Mixed Salt by ICP-AES,Chinese Journal of Spectroscopy Laboratory,30(6),2013. 